\title{
Peptide-based PET imaging of the tumor restricted IL13RA2 biomarker
}

\author{
Kiran Kumar Solingapuram Sai ${ }^{1, *}$, Anirudh Sattiraju ${ }^{1, *}{ }^{,}$Frankis G. Almaguel ${ }^{1}$, Ang \\ Xuan $^{1}$, Stephanie Rideout ${ }^{1}$, Rahul S. Krishnaswamy ${ }^{1}$, JoAnn Zhang ${ }^{2}$, Denise $M$. \\ Herpai $^{3}$, Waldemar Debinski ${ }^{3}$ and Akiva Mintz ${ }^{1}$ \\ ${ }^{1}$ Department of Radiology, Wake Forest School of Medicine, Winston-Salem, NC, USA \\ ${ }^{2}$ MicroPET/CT Imaging Section, TriFoil Imaging, Chatsworth, CA, USA \\ ${ }^{3}$ Department of Cancer Biology, Brain Tumor Center of Excellence, Wake Forest School of Medicine, Winston Salem, NC, USA \\ *These authors have contributed equally to this work \\ Correspondence to: Kiran Kumar Solingapuram Sai, email: ksolinga@wakehealth.edu \\ Akiva Mintz, email: amintz@wakehealth.edu \\ Keywords: positron emission tomography (PET), high-grade glioma, doxycycline, biodistribution, IL I3RA2 \\ Received: January 25, $2017 \quad$ Accepted: February 27, $2017 \quad$ Published: March 24, 2017 \\ Copyright: Sai et al. This is an open-access article distributed under the terms of the Creative Commons Attribution License 3.0 \\ (CC BY 3.0), which permits unrestricted use, distribution, and reproduction in any medium, provided the original author and source \\ are credited.
}

\section{ABSTRACT}

Peptides that target cancer cell surface receptors are promising platforms to deliver diagnostic and therapeutic payloads specifically to cancer but not normal tissue. IL13RA2 is a tumor-restricted receptor found to be present in several aggressive malignancies, including in the vast majority of high-grade gliomas and malignant melanoma. This receptor has been successfully targeted for diagnostic and therapeutic purposes using modified IL-13 ligand and more recently using a specific peptide, Pep-1L. In the current work, we establish the in vitro and in vivo tumor binding properties of radiolabeled Pep-1L, designed for tumor imaging. We radiolabeled Pep-1L with Copper-64 and demonstrated specific cell uptake in the IL13RA2-over expressing G48 glioblastoma cell line having abundant IL13RA2 expression. [ ${ }^{64} \mathrm{Cu}$ ]Pep-1L binding was blocked by unlabeled ligand, demonstrating specificity. To demonstrate in vivo tumor uptake, we intravenously injected into tumor-bearing mice and demonstrated that $\left[{ }^{64} \mathrm{Cu}\right] \mathrm{Pep}-1 \mathrm{~L}$ specifically bound tumors at 24 hours, which was significantly blocked (3-fold) by pre-injecting unlabeled peptide. To further demonstrate specificity of Pep-1L towards IL13RA2 in vivo, we exploited an IL13RA2-inducible melanoma tumor model that does not express receptor at baseline but expresses abundant receptor after treatment with doxycycline. We injected $\left[{ }^{64} \mathrm{Cu}\right] \mathrm{Pep}-1 \mathrm{~L}$ into mice bearing IL13RA2-inducible melanoma tumors and performed in vivo PET/CT and post-necropsy biodistribution studies and found that tumors that were induced to express IL13RA2 receptor by doxycycline pretreatment bound radiolabeled Pep-1L 3-4 fold greater than uninduced tumors, demonstrating receptor specificity. This work demonstrates that [ ${ }^{64} \mathrm{Cu}$ ]Pep-1L selectively binds hIL13RA2-expressing tumors and validates Pep-1L as an effective platform to deliver diagnostics and therapeutics to IL13RA2-expressing cancers.

\section{INTRODUCTION}

Peptides that target cancer cell surface receptors are a promising platform to deliver diagnostics and therapeutics specifically to transformed but not normal tissue $[1,2]$. PET/CT imaging using radiolabeled peptides can serve not only as a diagnostic test in itself [3] but also to stratify patients who express the particular biomarkers targeted by molecular therapies [4]. Examples of this PET-based stratification strategy were demonstrated to a priori predict response to common biomarker targeted therapies, including the estrogen receptor in breast cancer $[4,5]$. Furthermore, 
PET-based imaging can expedite clinical development of targeted therapeutic strategies by demonstrating in vivo ligand targeting, biodistribution and kinetics [6].

The goal of this work was to utilize PET/CT to demonstrate the feasibility of using a peptide-based targeted approach to image interleukin-13 receptor $\alpha 2$ (IL13RA2) expression in vivo for the purpose of translating this promising platform to deliver diagnostic and therapeutic payloads. We previously identified IL13RA2 as an attractive molecular target that is highly overexpressed in glioblastoma (GBM) but not in normal brain [7-14]. GBM is the most common primary brain cancer and is defined by high morbidity and almost inevitable mortality $[15,16]$. The median survival is less than 17 month with 5 -y survival rate of $<10 \%$. Many research studies are currently being carried out to improve the diagnostic and therapeutic strategies for GBM [16-18]. One such strategy is to develop GBM specific biomolecular agents that target IL13RA2 and are used as potential diagnostic markers, imaging tracers and drug candidates [19-21]. In addition to brain cancer, IL13RA2 has also been reported to be highly expressed in other deadly malignancies, including melanoma, head and neck, ovarian and pancreatic cancers [22-24]. We and others have designed and developed a number of molecular targeted therapies based on IL13 and its derivatives that have shown their efficacy in preclinical models of various cancers [13, 19, 20, 25-29]. In fact, our targeted IL13-based agents were recently used as targeting ligand in chimeric antigen receptor (CAR)-engineered $\mathrm{T}$ cells that are in clinical trials [30]. Early results from this trial have reported safe and even remarkable results, including a case of a GBM patient experiencing regression of all intracranial and spinal tumors [30]. As this and other types of therapies are implemented against IL13RA2 in peripheral cancers that widely express IL13RA2, it is critical to develop a molecular imaging technique to confirm uniform biomarker expression for patient stratification. Furthermore, such a ligand can be used as a platform to deliver therapeutic radiation and targeted chemotherapy. Peptide-based approaches offer an advantage due to their small size and fast clearance, which has been shown to potentially increase the tumorto-background ratio [31]. Furthermore, the ease of producing cGMP grade peptides is significantly easier than manufacturing properly folded targeted IL13 derivatives. Therefore, the focus of this study is to radiolabel Pep-1L, a novel peptide isolated from a hepta-peptide library that specifically binds to IL13RA2 [7, 32, 33] and determine its in vitro and in vivo tumor binding properties [34]. For peptide-based delivery platforms, Copper $64(\mathrm{Cu}-64)$ has become an attractive radionuclide in the development of a wide range of radiopharmaceuticals for PET due to its $\beta+$ emission, high specific activity, and half-life of 12 hours, which matches the kinetics of peptides [35]. Cu-64 easily binds to peptides through standard chelators $[35,36]$.
Therefore, to validate Pep-1L as an in vivo IL13RA2 targeting platform, we utilized PET/CT molecular imaging to visualize real-time $\mathrm{Cu}-64$ labeled Pep-1L binding to a standard IL13RA2-expressing tumor. Furthermore, we produced a novel inducible human (h) IL13RA2expressing melanoma tumor model to demonstrate specificity of Pep-1L to IL13RA2.

\section{RESULTS}

\section{Radiolabeling Pep-1L with Cu-64}

Extensive past studies involving radiolabeled peptides have demonstrated that 1,4,7-triazacyclononane1,4,7-triacetic acid (NOTA) is an optimal way to radiolabel peptides. It forms a 6-coordinate prismatic complex with $\mathrm{Cu}$ (II) by coordinating the lone pairs of the three nitrogen atoms and the three carboxylate groups of the chelator [35-38]. Therefore, we utilized NOTA conjugated Pep-1L to radiolabel with $\mathrm{Cu}-64$ using standard methodologies. NOTA conjugated Pep-1L was radiolabeled with $\mathrm{Cu}-64$ in $0.1 \mathrm{M} \mathrm{NH}_{4} \mathrm{OAc}$ buffer ( $\mathrm{pH} 5.5$ ) with $>98 \%$ radiochemical purity at $75^{\circ} \mathrm{C}$ for $1 \mathrm{~h}(\mathrm{n}=15)$ (Figure 1). The $\mathrm{R}_{\mathrm{f}}$ of the final radiolabeled product was $\sim 0.13$ while the unreacted $\mathrm{Cu}-64$ was $\sim 0.95$ on iTLC strips with $5 \mathrm{mM}$ EDTA solution as mobile phase. The radiolabeling of Pep-1L with $\mathrm{Cu}-64$ was tested over a wide range of aqueous buffer solutions with $\mathrm{pH}$ ranging from 4.0 to 7.5 and the highest radiochemical purity was achieved at $\mathrm{pH}$ 5.5. The radiolabeled peptide $\left[{ }^{64} \mathrm{Cu}\right] \mathrm{Pep}-1 \mathrm{~L}$ was used without any additional purification for both in vitro and in vivo studies.

\section{Serum stability of $\left[{ }^{64} \mathrm{Cu}\right] \mathrm{Pep}-1 \mathrm{~L}$}

The in vitro serum stability of the radiotracer $\left[{ }^{64} \mathrm{Cu}\right]$ Pep-1L in human serum was performed at different time points and was analyzed through radioTLC spotting (Figure 2). At $24 \mathrm{~h}$ post synthesis of $\left[{ }^{64} \mathrm{Cu}\right] \mathrm{Pep}-1 \mathrm{~L}$, $\sim 90 \%$ of the radioactive tracer remained intact. This data indicates that $\left[{ }^{64} \mathrm{Cu}\right] \mathrm{Pep}-1 \mathrm{~L}$ has good serum stability and suitable for in vivo use.

\section{In vitro cell uptake of $\left[{ }^{64} \mathrm{Cu}\right] \mathrm{Pep}-1 \mathrm{~L}$ in IL13RA2- expressing tumor cells}

An in vitro cell uptake assay was performed on G48 human glioblastoma cells with and without unlabeled Pep-1L as blocking agent to demonstrate the specificity and binding efficiency of $\left[{ }^{64} \mathrm{Cu}\right] \mathrm{Pep}-1 \mathrm{~L}$. Previously, we reported that this cell line contains about 4,000,000 IL13RA2 binding sites $[13,20,26,33] .\left[{ }^{64} \mathrm{Cu}\right]$ Pep$1 \mathrm{~L}$ bound these IL13RA2-expressing cells, which was significantly inhibited by binding site blockade with unlabeled Pep-1L (Figure 3). These in vitro uptake data demonstrate binding and specificity of $\left[{ }^{64} \mathrm{Cu}\right] \mathrm{Pep}-1 \mathrm{~L}$ towards IL-13RA2-expressing cancer cells. 


\section{Biodistribution studies in mice bearing human IL13RA2-expressing xenografts}

Biodistribution studies with $\left[{ }^{64} \mathrm{Cu}\right] \mathrm{Pep}-1 \mathrm{~L}$ were performed in mice bearing IL13RA2-expressing G48 tumors $(\mathrm{n}=4)$ to confirm in vivo binding. $\left[{ }^{64} \mathrm{Cu}\right]$ Pep$1 \mathrm{~L}$ displayed rapid clearance from most of the major organs from $4 \mathrm{~h}$ to $24 \mathrm{~h}$ post injection. However, tumor uptake steadily increased from $4 \mathrm{~h}$ to $24 \mathrm{~h}$ (Figure 4A) with $\% \mathrm{ID} / \mathrm{g}$ of $1.38 \pm 0.09(4 \mathrm{~h})$ and $2.43 \pm 0.63(24 \mathrm{~h})$. The uptake ratios for target to non-target (tumor: muscle) increased from 3.7 to 6.0 from $4 \mathrm{~h}$ to $24 \mathrm{~h}$ (Figure 4B). Importantly, the tumor uptake was significantly blocked (5-fold) in mice pretreated with unlabeled peptide $(\mathrm{n}=4)$ after $24 \mathrm{~h}$ post injection i.e., $\% \mathrm{ID} / \mathrm{g}=2.43 \pm 0.626$ in the nonblockade group Vs. $0.49 \pm 0.128$ in the blockade group, demonstrating radiotracer specificity (Table 1).

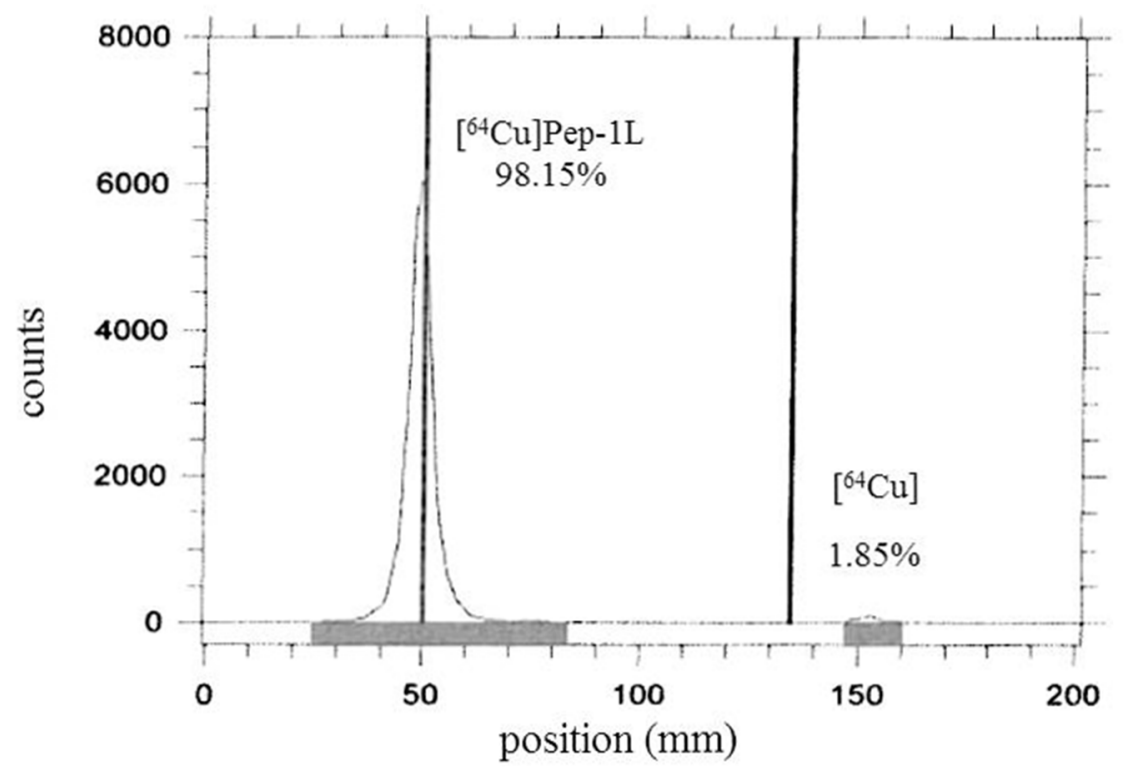

Figure 1: RadioTLC analysis of $\left[{ }^{64} \mathbf{C u}\right]$ Pep-1L. Analysis demonstrates $98.15 \%$ radiochemical purity $(5 \mathrm{mM}$ EDTA solution as mobile phase on an iTLC plate).

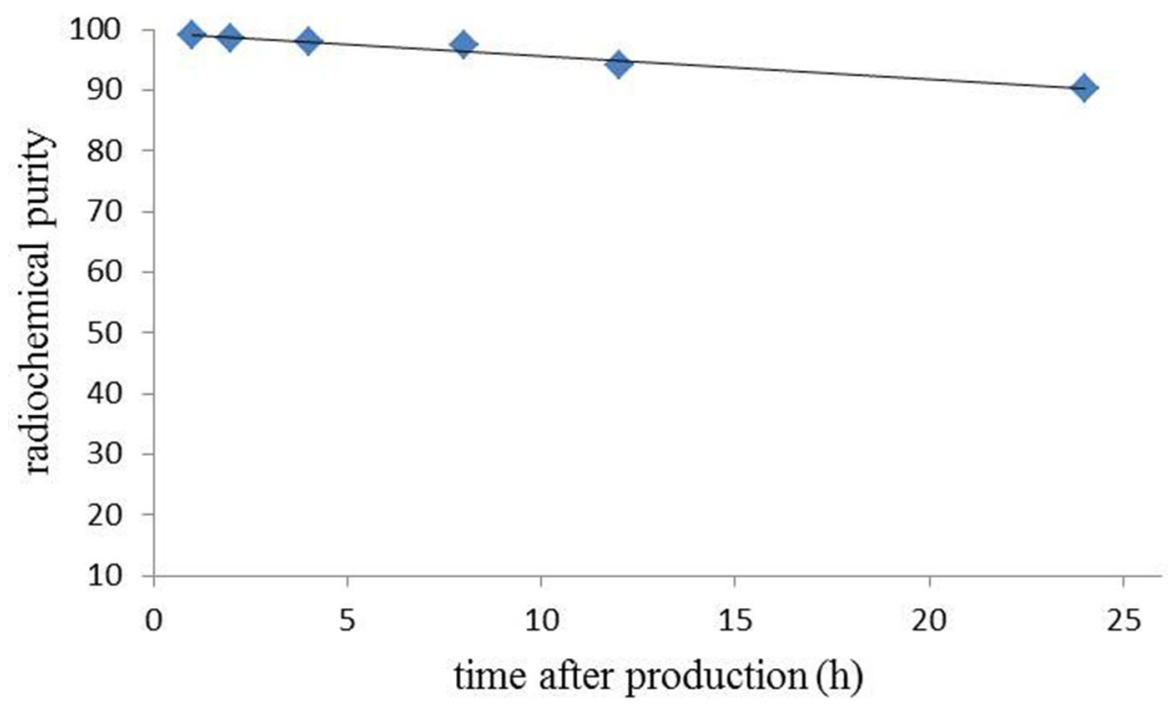

Figure 2: In vitro serum stability of $\left[{ }^{64} \mathrm{Cu}\right] \mathrm{Pep}-1 \mathrm{~L}$. Reverse-phase $\mathrm{C} 18$ radio-TLC analysis of $\left[{ }^{64} \mathrm{Cu}\right] \mathrm{Pep}-1 \mathrm{~L}$ over a 24 hour period post production. 


\section{$\left[{ }^{64} \mathrm{Cu}\right] \mathrm{Pep}-1 \mathrm{~L}$ specifically binds doxycycline induced B16F10-Tet-hIL13RA2 tumors in vivo}

To further confirm the in vivo specificity of $\left[{ }^{64} \mathrm{Cu}\right]$ Pep-1L to IL13RA2, we created a novel IL13RA2inducible cell line. B16F10 murine melanoma cells, which do not endogenously express IL13RA2, were transfected with a tetracycline inducible plasmid expressing both mCherry and hIL13RA2 (Figure 5A). Upon induction with doxycycline, mCherry fluorescence $(610 \mathrm{~nm})$ was observed in vitro, confirming successful transfection and induction of reporter gene (Figure 5B). Single colonies were generated by serially diluting cell suspensions of B16F10-Tet-hIL13RA2 cells and a high IL13RA2expressing doxycycline inducible clone was selected for further studies. Importantly, we observed a proportional increase hIL13RA2 expression with increasing concentrations of doxycycline (Figure 5C).

To demonstrate in vivo receptor specificity of $\left[{ }^{64} \mathrm{Cu}\right]$ Pep-1L, hIL13RA2-induced B16 tumors were generated by injecting mice flanks with B16F10-Tet-hIL13RA2 cells. 7 days after tumor cell implantations, mice were

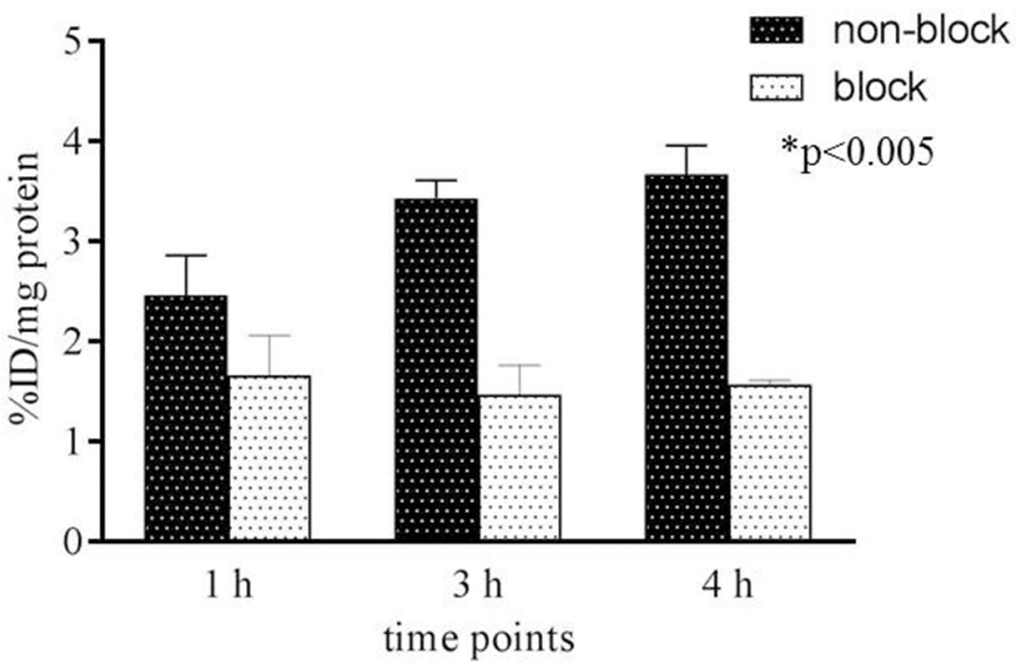

Figure 3: Cell uptake of $\left[{ }^{64} \mathbf{C u}\right]$ Pep-1L. Uptake of $\left[{ }^{64} \mathrm{Cu}\right] \mathrm{Pep}-1 \mathrm{~L}$ in IL13RA2-expressing G48 cells after 1, 3, and $4 \mathrm{~h}$ of exposure. Receptor blockade experiments were performed to demonstrate specificity by exposing cells to 50x excess unlabeled peptide, 15 min prior to adding radiolabeled peptide to saturate binding sites. The data were expressed as $\%$ injected dose (ID)/mg of protein present in each well with $p$ values $\leq .005$ considered statistically significant $(\mathrm{n}=6)$.
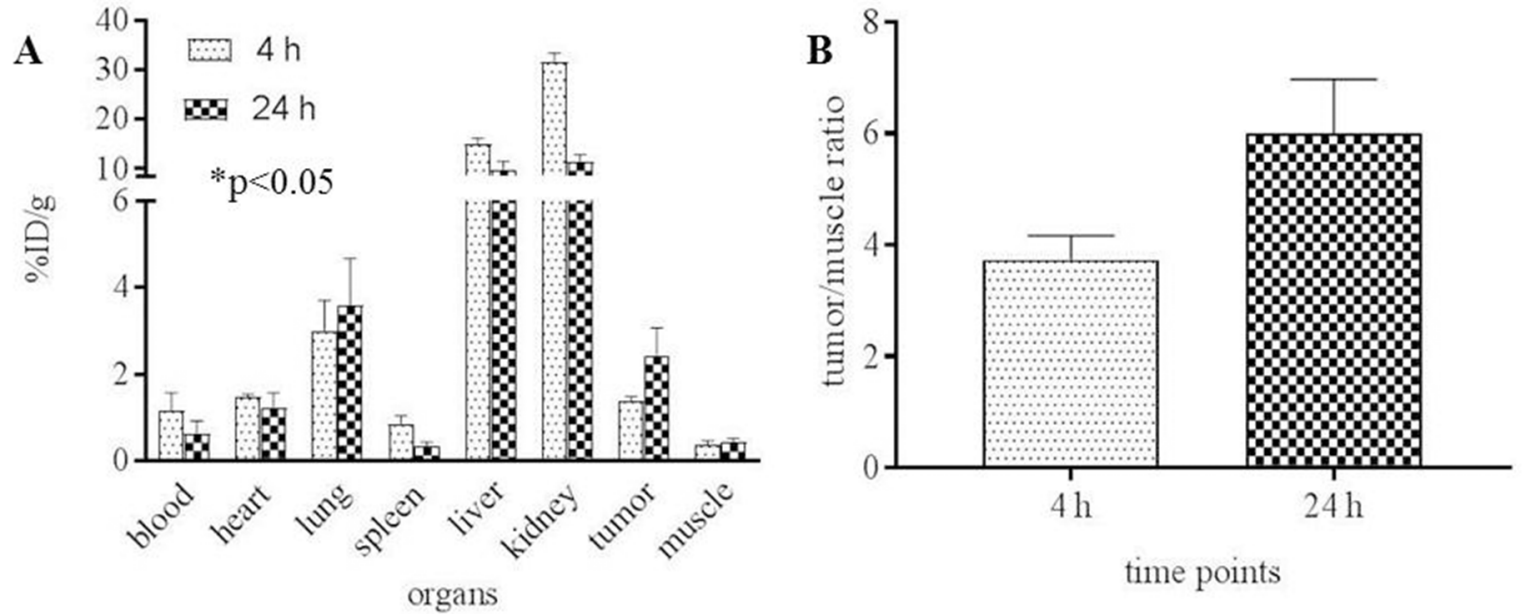

Figure 4: In vivo properties of $\left[{ }^{64} \mathrm{Cu}\right] \mathrm{Pep}-1 \mathrm{~L}$ (A) biodistribution and (B) tumor-to-muscle (target: nontarget) ratio of $\left[{ }^{64} \mathrm{Cu}\right]$ Pep-1L in mice bearing IL13RA2-expressing tumor xenografts $4 \mathrm{~h}$ and $24 \mathrm{~h}$ post injection $(\mathrm{n}=4)$ with $\mathrm{p}$ values $\leq .05$ considered statistically significant. 
Table 1: Biodistribution of $\left[{ }^{64} \mathrm{Cu}\right] \mathrm{Pep}-1 \mathrm{~L}$ in tumor bearing mice: non-blockade and blockade $24 \mathrm{~h}$ post injection with $p$ values $\leq .05$ considered statistically significant $(n=4)$

\begin{tabular}{|c|c|c|}
\hline Organs & $\begin{array}{c}24 \text { h non-blockade } \\
(\% \mathrm{ID} / \mathrm{g} \pm \mathrm{SD})\end{array}$ & $\begin{array}{l}24 \mathrm{~h} \text { blockade } \\
(\% \mathrm{ID} / \mathrm{g} \pm \mathrm{SD})\end{array}$ \\
\hline Heart & $1.21 \pm 1.012$ & $1.86 \pm 1.012$ \\
\hline Blood & $0.62 \pm 0.579$ & $1.04 \pm 0.793$ \\
\hline Lung & $3.58 \pm 1.078$ & $3.41 \pm 0.781$ \\
\hline Liver & $9.86 \pm 1.593$ & $6.59 \pm 0.395$ \\
\hline Kidney & $17.45 \pm 1.412$ & $9.75 \pm 2.140$ \\
\hline Tumor & $2.43 \pm 0.626$ & $0.49 \pm 0.128$ \\
\hline Muscle & $0.41 \pm 0.038$ & $0.345 \pm 0.164$ \\
\hline
\end{tabular}

A

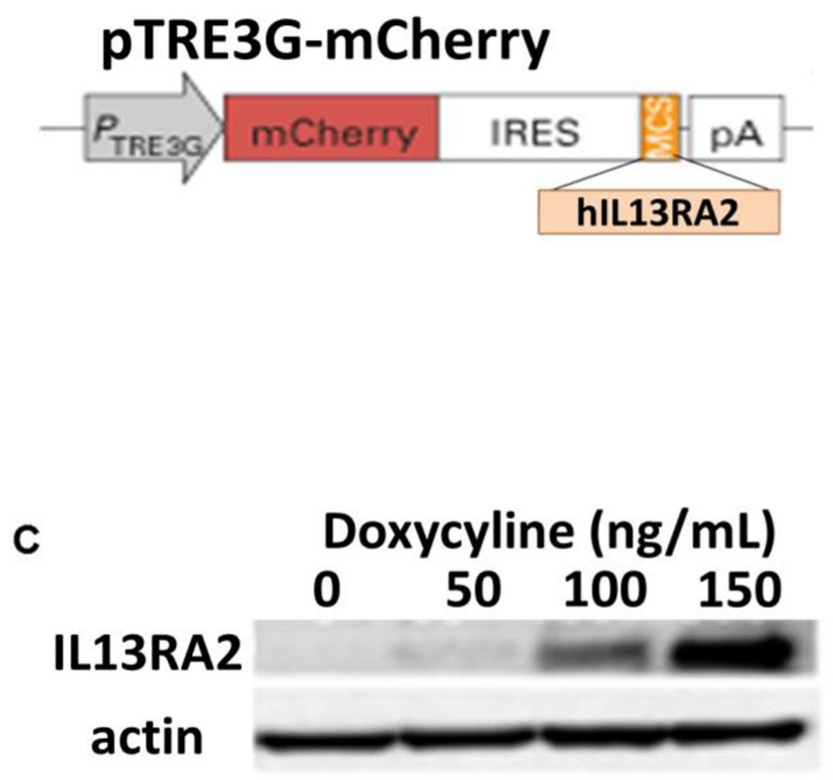

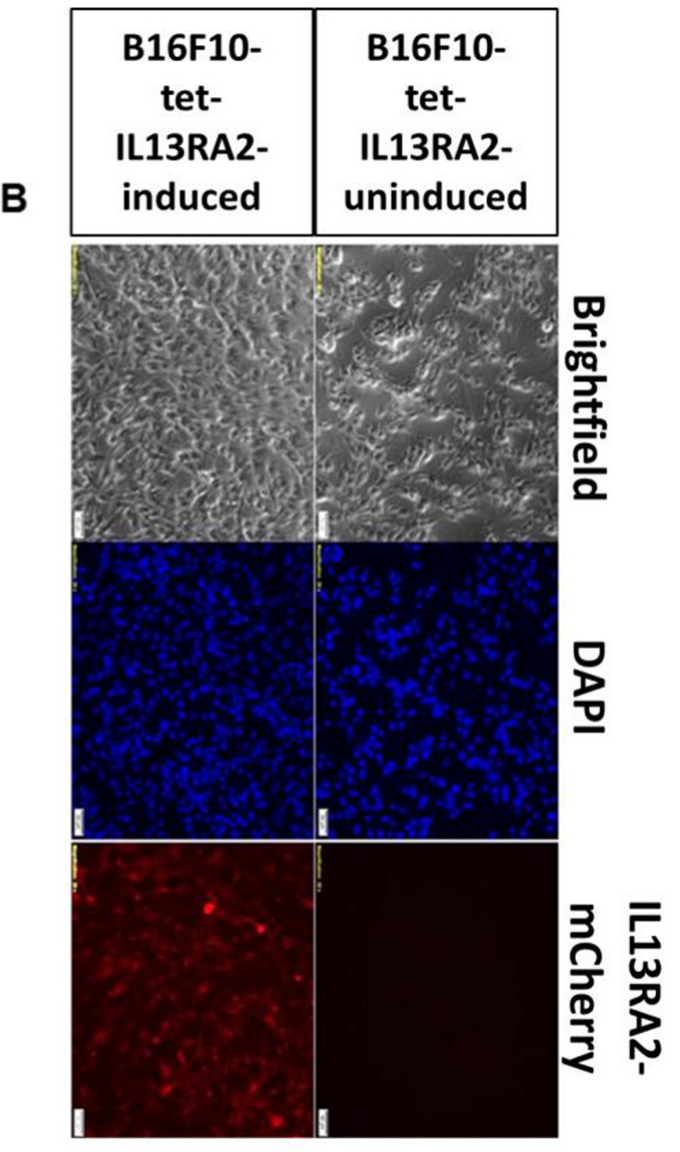

Figure 5: Characterization of inducible hIL13RA2 expressing cells. (A) Scheme of inducible hIL13RA2 expressing plasmid. The receptor sequence was cloned into the pTRE3G vector that contains a tetracycline inducible promoter (TRE3G), which drives expression of the mCherry fluorescent reporter and hIL13RA2 (B) Induced mCherry fluorescence tag visualized under a fluorescent microscope. mCherry fluorescence is seen only in doxycycline induced clone $18 \mathrm{~B} 16 \mathrm{~F} 10$ cells in vitro. Non-induced clone $18 \mathrm{~B} 16 \mathrm{~F} 10$ cells show lack of mCherry fluorescence. Doxycycline activated production of hIL13RA2 protein in B16F10 clone 18 cell line. (C) Western blotting using antibody for hIL13RA2 shows proportionally increasing levels of hIL13RA2 as concentration of doxycycline increases. 
divided into induced and uninduced (control) groups $(n=4 /$ group). To induce hIL13RA2 expression, doxycycline was administered intraperitoneally $(2.5 \mathrm{mg} / \mathrm{mouse})$ every 12 hours for 2 days [39, 40]. After IL13RA2-induction, $\left[{ }^{64} \mathrm{Cu}\right] \mathrm{Pep}-1 \mathrm{~L}$ was intravenously injected to mice bearing induced or control (uninduced) subcutaneous tumors and microPET/CT imaging was performed $4 \mathrm{~h}$ post intravenous injection. ROI analysis of micro PET/CT imaging data showed that $\left[{ }^{64} \mathrm{Cu}\right] \mathrm{Pep}-1 \mathrm{~L}$ accumulation was $~ 3$-fold greater in doxycycline-induced B16F10-TethIL13RA2 tumor bearing mice compared to non-induced ones (Figure 6A) demonstrating specificity of $\left[{ }^{64} \mathrm{Cu}\right]$ Pep$1 \mathrm{~L}$ to IL13RA2 expressing tumors. These results were

\section{A}

\section{IL13RA2-negative (control)}
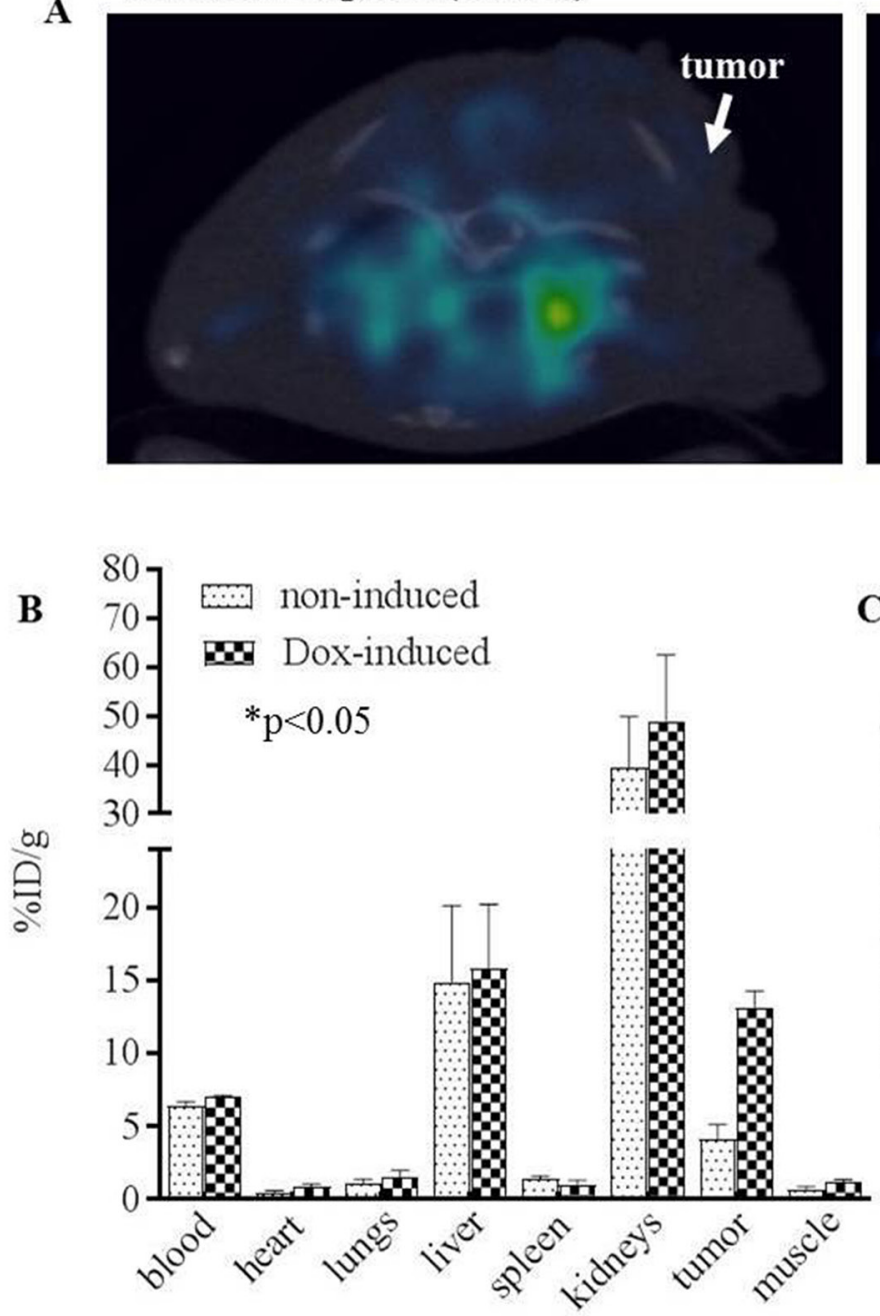

organs corroborated in the post-PET biodistribution studies that demonstrated significant tumor uptake in the hIL13RA2induced tumors compared to the non-induced controls (Figure $6 \mathrm{~B}$ and $6 \mathrm{C}$ ). $\left[{ }^{64} \mathrm{Cu}\right] \mathrm{Pep}-1 \mathrm{~L}$ demonstrated $\sim 4.0$ fold greater accumulation in the tumor of doxycycline-induced tumor bearing mice $(\% \mathrm{ID} / \mathrm{g}=14.09 \pm 0.246)$ compared to non-induced tumor bearing mice $(\% \mathrm{ID} / \mathrm{g}=4.179 \pm$ 0.007) (Figure 6B). Other notable findings were that there was radiotracer accumulation in liver and kidney in both induced and control animals, which are primary organs for peptide clearance. These biodistribution results were consistent with the microPET imaging data and confirmed in vivo targeting of Pep-1L.

\section{IL13RA2-positive (induced)}
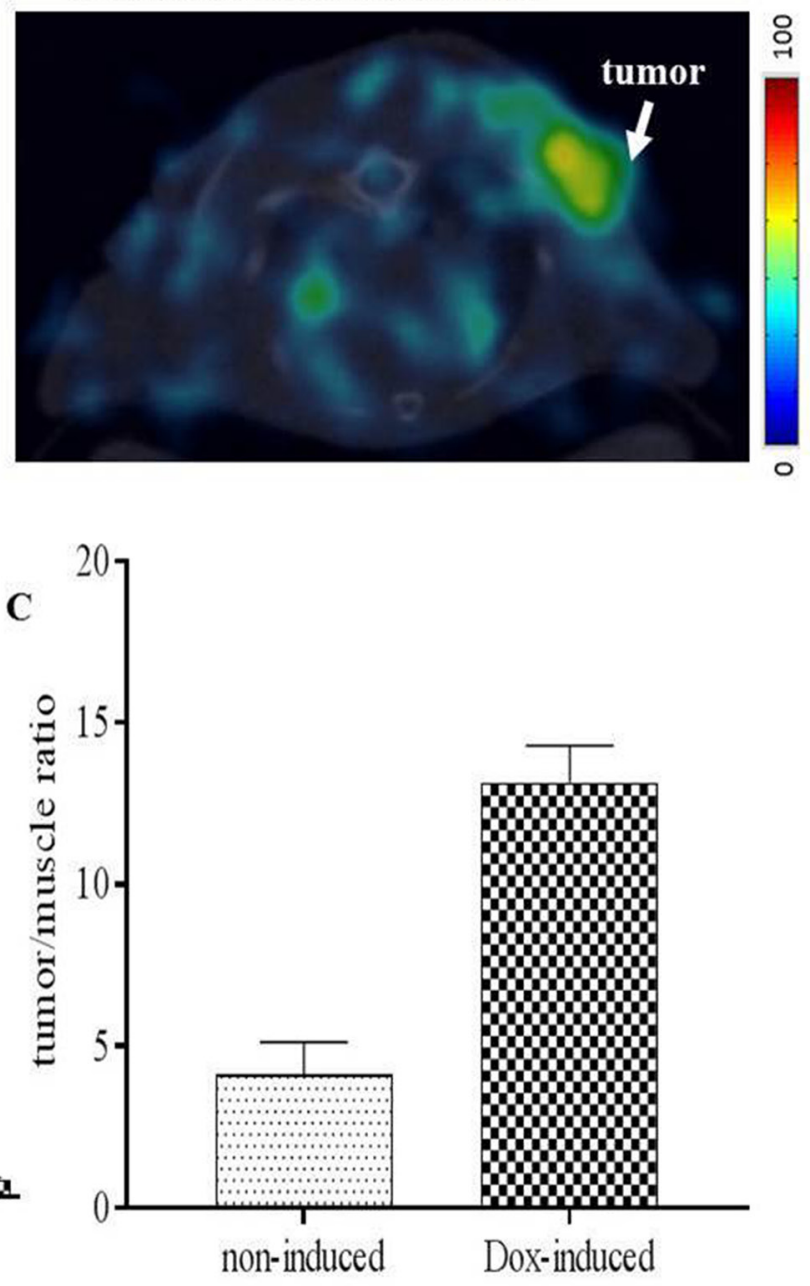

Figure 6: PET/CT of $\left[{ }^{64} \mathrm{Cu}\right] \mathrm{Pep}-1 \mathrm{~L}$ targeting IL13RA2 expressing tumors. Representative axial fused microPET/CT images obtained after injection of $\left[{ }^{64} \mathrm{Cu}\right] \mathrm{Pep}-1 \mathrm{~L}$ in a novel doxycycline inducible IL3RA2 tumor model. (A) PET/CT of IL13RA2-induced and uninduced tumor-bearing mice at $4 \mathrm{~h}$ post injection. (B) Post-PET biodistribution analysis shows $\left[{ }^{64} \mathrm{Cu}\right] \mathrm{Pep}-1 \mathrm{~L}$ specifically accumulates in hIL13RA2 expressing induced B16F10 tumors with absolute values in $\% \mathrm{ID} / \mathrm{g}$ with with $p$ values $\leq .05$ considered statistically significant $(\mathrm{n}=4)$ and $(\mathbf{C})$ tumor/muscle ratios of $\left[{ }^{64} \mathrm{Cu}\right]$ Pep-1L accumulation in hIL13RA2-expressing B16F10 tumors compared to uninduced control tumors. 


\section{DISCUSSION}

The ability to target a specific receptor that is highly expressed on the surface of cancer cells creates the opportunity to use targeted peptides as highly selective platforms to deliver diagnostic and therapeutic payloads to cancer [31]. Therefore, in this work we used translational PET imaging to demonstrate the in vivo targeting of Pep-1L, a peptide reported to target IL13RA2 [7], an attractive tumor-associated biomarker that we and others have demonstrated to be present on a number of deadly malignancies, including GBM and melanoma [13, 41, 42].

Pep-1L was conjugated with NOTA, a chelator that can form a six-coordinate complex with $\mathrm{Cu}-64$ that results in a high stability constant $(\log \mathrm{K}=21.6)$ by $\mathrm{CPC}$ scientific Inc. [34]. This is more stable that than other commonly used chelators, such as TETA or DOTA [43]. The Cu-64 radiolabeling conditions for Pep-1L were well optimized in this work for high radiochemical purity of $>98 \%$, without any need for additional purification methodologies with a specific activity of 32-35 MBq/ $\mu \mathrm{g}$ (Figure 1). Importantly, $\left[{ }^{64} \mathrm{Cu}\right] \mathrm{Pep}-1 \mathrm{~L}$ demonstrated in vitro serum stability $(\sim 90 \%$ intact for $24 \mathrm{~h}$ ), demonstrating translational significance (Figure 2).

To demonstrate in vitro cell uptake, we performed binding studies on the G48 GBM cell line that we previously established to express 4,000,000 IL13RA2 binding sites. These studies demonstrated high tumor cell uptake, which was significantly blocked by unlabeled Pep-1L, showing specificity (Figure 3). Importantly, uptake was maintained over time and was still present in high levels at $4 \mathrm{~h}$, which is expected due to known internalization properties of Pep-1L, indicating the suitability of this peptide as a carrier of potential therapeutics. We initially confirmed $\left[{ }^{64} \mathrm{Cu}\right] \mathrm{Pep}-$ $1 \mathrm{~L}$ 's tumor binding properties in vivo in mice bearing IL13RA2-expressing G48 tumors (Figure 4) and found specific binding at 24 hours, which was blocked (3fold blockade) by pre-injecting unlabeled peptide (Table 1). There was minimal $(\% \mathrm{ID} / \mathrm{g} \sim 0.013 \pm 0.005$ at $4 \mathrm{~h}$ and $\sim 0.009 \pm 0.003$ at $24 \mathrm{~h}$ ) or no radiotracer uptake in the brain at these delayed times, indicating no peptide residence or binding. However, further studies are currently being performed to evaluate dynamic uptake in normal brain as well as in brains containing orthotopic tumors. To further validate the specificity of $\left[{ }^{64} \mathrm{Cu}\right] \mathrm{Pep}-1 \mathrm{~L}$ in vivo, we produced a novel inducible hIL13RA2 expressing murine melanoma cell line that we demonstrated expresses IL13RA2 only after induction with doxycycline (Figure 5). Importantly, doxycyclineinduced B16F10-Tet-IL13RA2 subcutaneous tumors demonstrated significantly more $\left[{ }^{64} \mathrm{Cu}\right] \mathrm{Pep}-1 \mathrm{~L}$ uptakeon PET/CT imaging compared to uninduced controls (Figure 6). These results were confirmed on Post-PET biodistribution analysis (Figure 6) and further validate the specific binding of $\left[{ }^{64} \mathrm{Cu}\right] \mathrm{Pep}-1 \mathrm{~L}$ to IL13RA2.
Receptor targeted platforms like Pep-1L are increasingly being used to target chemotherapies and radiation to cancer [44, 45]. IL13RA2 is especially attractive due to its ubiquitous expression on GBM, melanoma and other cancers. Furthermore, IL13RA2 has been shown to be internalized together with its ligand and attached payload [7, 46]. This property of Pep-1L was initially described by Pandya et al [33] but confirmed in our current study, as we saw a continued increase in $\left[{ }^{64} \mathrm{Cu}\right] \mathrm{Pep}-1 \mathrm{~L}$ uptake from 1 to 4 hours. In addition to demonstrating tumor targeting and therapeutic potential of Pep-1L, we also developed a translational companion diagnostic that can be used to demonstrate real-time IL13RA2 expression in tumors. Knowing each tumor's IL13RA2 expression profile can help personalize IL13RA2-targeted therapies to patients that have tumors that express significant amounts of IL13RA2.

\section{CONCLUSION}

This work demonstrates that $\left[{ }^{64} \mathrm{Cu}\right] \mathrm{Pep}-1 \mathrm{~L}$ selectively binds hIL13RA2-expressing tumors and validates Pep-1L as an effective platform to deliver diagnostics and therapeutics to IL13RA2-expressing cancers.

\section{MATERIALS AND METHODS}

\section{Chelators and chemicals}

The sequence of the Pep-1L peptide was as follows: H-Ala-Cys-GlyGlu-Met-Gly-Trp-Val-Arg-Cys-Gly-GlyGly-Ser-LCLys-Lys(biotin)- $\mathrm{NH}_{2}$. Pep-1L conjugated to NOTA was purchased from CPC scientific ltd, Sunnyvale, CA. All reagents were purchased from Sigma-Aldrich, St. Louis, MO and were used without additional purification. Reversed phase TLC plates were purchased from Whatman Inc, Florham Park, NJ.

\section{Radiolabeling procedure}

Copper-64 ( $\left.{ }^{64} \mathrm{Cu}: \mathrm{t}_{1 / 2}=12.7 \mathrm{~h}\right)$ was purchased from Washington University in St. Louis. The custom PeptideNOTA was conjugated by CPC scientific Inc. Custom Peptide-NOTA was radiolabeled with ${ }^{64} \mathrm{Cu}$ according to the previously reported methods [35, 36, 38, 47]. Briefly, $20 \mu \mathrm{g}$ of NOTA-Peptide was dissolved in $0.1 \mathrm{M}$ ammoniumacetate $\left(\mathrm{NH}_{4} \mathrm{OAc}\right)$ aqueous buffer solution $\mathrm{pH}$ 5.5. ${ }^{64} \mathrm{CuCl}_{2}$ was converted to ${ }^{64} \mathrm{Cu}(\mathrm{OAc}){ }_{2}{ }^{64} \mathrm{Cu}$-acetate $)$ by dissolving in $100 \mu \mathrm{L}$ of $0.1 \mathrm{M} \mathrm{NH}_{4} \mathrm{OAc} \mathrm{pH}$ 5.5. The resultant ${ }^{64} \mathrm{Cu}(\mathrm{OAc})_{2}$ was then added to the conjugated NOTA-Peptide aliquot in an Eppendorf tube and heated at $75^{\circ} \mathrm{C}$ for $1 \mathrm{~h}$. Radiochemical purity was determined by radio-TLC (MK-C18 reversed phased TLC plates). Around $\sim 1 \mu \mathrm{L}$ of the reaction mixture was applied on the C18-reversed phase TLC plate and developed with 
$10 \% \mathrm{NH}_{4} \mathrm{OAc}: \mathrm{MeOH}(30: 70)$ as the mobile phase. After the completion of reaction (through TLC analysis), the reaction mixture was quenched with $5 \mathrm{mM}$ EDTA aqueous solution and stirred for an additional $15 \mathrm{~min}$ at $30^{\circ} \mathrm{C}$. The final product was passed through $0.22 \mu \mathrm{m}$ filter and reanalyzed by iTLC strips with $5 \mathrm{mM}$ EDTA solution as mobile phase. The TLC plates were scanned on a BioScan Imaging Scanner.

\section{Serum stability}

The in vitro serum stability of $\left[{ }^{64} \mathrm{Cu}\right] \mathrm{Pep}-1 \mathrm{~L}$ was performed using human serum (Sigma Aldrich) following previously published methods [38, 48]. Approximately $0.037 \mathrm{MBq} / 10 \mu \mathrm{L}$ of $\left[{ }^{64} \mathrm{Cu}\right] \mathrm{Pep}-1 \mathrm{~L}$ was added to the serum vial, to a final volume of $100 \mu \mathrm{L}$ and incubated at $37^{\circ} \mathrm{C}$ [35]. $1 \mu \mathrm{L}$ of the sample mixture was removed and spotted on a reverse C18-TLC plate at $1 \mathrm{~h}, 2 \mathrm{~h}, 4 \mathrm{~h}, 18 \mathrm{~h}$ and $24 \mathrm{~h}$ after the radiotracer synthesis and the percentage of bound $\mathrm{Cu}-64$ was determined through radioTLC analysis as mentioned above [48].

\section{Cell culture}

Human glioblastoma cell line G48 and murine melanoma cell line (ATCC) B16F10 were cultured in DMEM (Gibco) base media supplemented with 10\% (v/v) Fetal Bovine Serum (Invitrogen) and 1\% Antianti (Gibco). Following washing, cells were spun down, resuspended in growth media and counted using a hemocytometer.

\section{In vitro cell uptake assay}

The in vitro reactivity, binding affinity and specificity for $\left[{ }^{64} \mathrm{Cu}\right] \mathrm{Pep}-1 \mathrm{~L}$ were determined using human GBM cell line G48, following previously reported methods $[34,38,49] .1 \times 10^{5}$ cells were then seeded into each well of a 6-well culture. G48 cells were incubated overnight at $37^{\circ} \mathrm{C}$ with $5 \% \mathrm{CO}_{2}$ in an incubator. On the day of the assay, fresh solution of peptide was made at a concentration of $5 \mu \mathrm{M}$ in the respective cell media and was used as the blocker solution. The blocker solution was added $15 \mathrm{~min}$ prior to addition of radiotracer. G48 cells were incubated with $\left[{ }^{64} \mathrm{Cu}\right] \mathrm{Pep}-1 \mathrm{~L}(0.0185 \mathrm{MBq} /$ well $)$ for $1 \mathrm{~h}, 3 \mathrm{~h}$ and $4 \mathrm{~h}(\mathrm{n}=3)$ at $37^{\circ} \mathrm{C}$. The cell uptake assays were initiated by rinsing the cells with $2 \times 2 \mathrm{~mL}$ of the phosphate buffer at room temperature. Uptake was allowed to proceed for selected time periods and then terminated by rinsing the cell wells with $1 \mathrm{~mL}$ of the ice-cold buffer solution. Residual fluid was removed by pipette, and $200 \mu \mathrm{L}$ of $0.1 \%$ aqueous sodium dodecylsulfate lysis buffer solution was added to each well. The plate was then agitated at room temperature and $1 \mathrm{~mL}$ of the lysate was taken from each well for gamma counting [49]. The radioactivity was counted using the Wallac 1480 Wizard gamma counter (Perkin Elmer, Turku, Finland).
Additional $20 \mu \mathrm{L}$ aliquots were taken in triplicate from each well for protein concentration determination using the Pierce bicinchoninic acid protein assay kit method (Rockford, IL).

The uptake data in each sample from each well and the standard counts for each condition were expressed as counts per minute (cpm) of activity and were decay corrected for elapsed time. The cpm values of each well were normalized to the amount of radioactivity added to each well and the protein concentration in the well and expressed as percent uptake relative to the control condition. The data were expressed as $\% \mathrm{ID} / \mathrm{mg}$ of protein present in each well with $p$ values $\leq 0.005$ considered statistically significant.

\section{Biodistribution studies in tumor bearing mice}

Athymic nude mice (Taconic Farms) were housed in a pathogen-free facility of the Animal Research Program at Wake Forest School of Medicine under a 12:12-h light/ dark cycle and fed ad libitum. All animal experiments were conducted under IACUC approved protocols in compliance with the guidelines for the care and use of research animals established by Wake Forest Medical School Animal Studies Committee. IL13RA2-expressing G48 tumors cells ( $1 \times 10^{5}$ cells suspended in $\left.10 \mu \mathrm{L}\right)$ were implanted in the left flank of nude mice (25-30 g) as described previously $[10,13]$. The presence of viable tumors was confirmed through bioluminescence imaging. Standard biodistribution studies were performed in the same nude mice with flank tumors $(n=4)$ at $10-15$ days after tumor implantation. Mice were anesthetized with $1 \%$ isoflurane-oxygen and approximately 3.7-4.6 MBq of $\left[{ }^{64} \mathrm{Cu}\right] \mathrm{Pep}-1 \mathrm{~L}$ was administered via tail vein injection. To demonstrate specific binding, blocking experiments were performed on the mice from the $24 \mathrm{~h}$ time point group ( $\mathrm{n}=4 /$ group). Peptide concentration of $15 \mathrm{mg} / \mathrm{kg}$ was used as the blocking agent and was intravenously injected via tail vein $15 \mathrm{~min}$ prior to the radiotracer. The tumor and organs of interest were dissected and gamma counted using Wallac 1480 Wizard gamma counter (Perkin Elmer, Turku, Finland). The concentration of the radioactivity in the tumor and organs were expressed in percentage injected dose per gram $(\% \mathrm{ID} / \mathrm{g})$ of radioactivity with $p$ values $\leq .05$ considered statistically significant and uptake ratio of tumor-to-muscle was calculated.

\section{Generation and analysis of IL13RA2-inducible B16F10 melanoma tumors}

To create the inducible system, B16F10 melanoma cells were stably transfected with pCMV-Tet3G (Clontech), which encodes for the advanced Tet-On $3 \mathrm{G}$ transactivator element under constitutive $\mathrm{CMV}$ expression using standard cloning methods [50]. Cells were then stably transfected with the pTRE3G-mCherry- 
IRES-IL13RA2 plasmid, which encodes proportional expression of mCherry (bottom) and human IL13RA2 under the Tet-On promoter. Single colonies were isolated using serial dilution in 96 well plates and clones were analyzed for IL13RA2 expression via Western blot using methods we previously described [50]. For analysis of RFP expression, an inverted motorized fluorescent microscope (Olympus IX81) with an Orca-R2 Hamamatsu CCD camera (Hamamatsu) and a laser scanning confocal microscope (Olympus FluoView1200) were used for image acquisition. Camera drive and acquisition were performed using a MetaMorph Imaging System (Olympus) and FluoView 4.2 software were used for image acquisition.

\section{Subcutaneous implantation of B16F10 cell line}

B16F10 murine melanoma cell line was cultured in DMEM base media. Cells were harvested using trypsinEDTA (Gibco) after removing DMEM media from flasks and washing residual with DPBS (Lonza). Cell number was calculated using a hemocytometer and required number of B16F10 cells was suspended in DMEM media. The cell suspension was then mixed with growth factor reduced matrigel (Corning) in a 1:1 ratio and placed on ice. Athymic nude mice were anesthetized using isoflurane and injected with 1 million cells (in matrigel) subcutaneously near the left shoulder using $28 \mathrm{G}$ insulin syringes while being placed on a heating pad. Mice were then earmarked for identification and placed back in their cages.

\section{Doxycycline administration for IL13RA2- induction in mice bearing subcutaneous B16F10- Tet-hIL13RA2 tumors}

Tumor bearing athymic nude mice were grouped into two groups $(n=4)$. Two days prior the radiotracer injection and PET study, doxycycline ( $2.5 \mathrm{mg} / \mathrm{mouse})$ was administered intraperitoneally to one group of mice $(n=4)$ every $12 \mathrm{~h}$.

\section{PET/CT and post-necropsy biodistribution studies in mice bearing subcutaneous B16F10- Tet-IL13RA2 tumors}

Mice bearing subcutaneous tumors were grouped into two groups $(\mathrm{n}=4)$ and placed in an induction chamber containing $\sim 2 \%$ isoflurane/oxygen then secured to a custom double bed for placement of tail vein catheters. Anesthesia was maintained via nose-cone at $\sim 1 \%$ isoflurane/oxygen for the dynamic imaging procedure. The mice were injected with 4.62-5.5 MBq $\left[{ }^{64} \mathrm{Cu}\right] \mathrm{Pep}-1 \mathrm{~L}$ and scanned for $20 \mathrm{~min}$ using TriFoil PET/CT scanner $4 \mathrm{~h}$ post injection. The regions of interest (ROIs) were generated for both dox-treated and non-induced mice from manually drawn regions of interests. After the completion of microPET data acquisition, mice were euthanized for a confirmatory biodistribution studies. Samples of tumor, blood, lung, liver, spleen, kidney, muscle and heart were harvested, weighed and then counted on the gamma counter with a standard dilution of the injectate. The percentage of the injected dose per gram of tissue $(\% \mathrm{ID} / \mathrm{g})$ was calculated as described above with $p$ values $\leq .05$ considered statistically significant $(n=4)$.

\section{CONFLICTS OF INTEREST}

The authors declare no conflicts of interest.

\section{FUNDING}

This work was supported by the American Cancer Society Mentored Research Scholar grant \# 124443-MRSG-13-121-01-CDD (Mintz), the National Institute of Health (NIH) grant \#1R01CA17907201A1 (Mintz), P30 CA012197, R01 CA184091-01, R01CA74145 (Debinski) and the Translational Imaging Program (TIP) of the Wake Forest CTSA (UL1TR001420).

\section{REFERENCES}

1. Krenning EP, Kooij PP, Bakker WH, Breeman WA, Postema PT, Kwekkeboom DJ, Oei HY, de Jong M, Visser TJ, Reijs AE, Lamberts SW. Radiotherapy with a Radiolabeled Somatostatin Analogue, [ ${ }^{111}$ In-DTPA-d-Phe1]-Octreotide. Annals of the New York Academy of Sciences. 1994; 733: 496-506. doi: 10.1111/j.1749-6632.1994.tb17300.x.

2. Vaidyanathan G, Boskovitz A, Shankar S, Zalutsky MR. Radioiodine and 211 At-labeled guanidinomethyl halobenzoyl octreotate conjugates: potential peptide radiotherapeutics for somatostatin receptor-positive cancers. Peptides. 2004; 25: 2087-97.

3. Wehrenberg-Klee E, Redjal N, Leece A, Turker NS, Heidari P, Shah K, Mahmood U. PET imaging of glioblastoma multiforme EGFR expression for therapeutic decision guidance. American Journal of Nuclear Medicine and Molecular Imaging. 2015; 5: 379-89.

4. Gaykema SB, Brouwers AH, Lub-de Hooge MN, Pleijhuis RG, Timmer-Bosscha H, Pot L, van Dam GM, van der Meulen SB, de Jong JR, Bart J, de Vries J, Jansen L, de Vries EG, et al. 89Zr-Bevacizumab PET Imaging in Primary Breast Cancer. Journal of Nuclear Medicine. 2013; 54: 1014-8. doi: 10.2967/jnumed.112.117218.

5. Linden HM, Stekhova SA, Link JM, Gralow JR, Livingston RB, Ellis GK, Petra PH, Peterson LM, Schubert EK, Dunnwald LK. Quantitative fluoroestradiol positron emission tomography imaging predicts response to endocrine treatment in breast cancer. Journal of Clinical Oncology. 2006; 24: 2793-9.

6. Van Dongen GA, Visser GW, Lub-de Hooge MN, De Vries EG, Perk LR. Immuno-PET: a navigator in monoclonal 
antibody development and applications. The oncologist. 2007; 12: 1379-89.

7. Pandya H, Garg S, Gibo DM, Kridel S, Debinski W. Selection eletion of a linear heptapeptide that binds interleukin 13 receptor alpha 2 at a site distinct from the native ligand neuro-oncology. Durham, North Carolina: Duke University Press; 2009. pp. 597.

8. Debinski W, Slagle B, Gibo DM, Powers SK, Gillespie GY. Expression of a Restrictive Receptor for Interleukin 13 is Associated with Glial Transformation. Journal of Neuro-Oncology. 2000; 48: 103-11. doi: 10.1023/a:1006446426611.

9. Debinski W, Gibo DM. Molecular expression analysis of restrictive receptor for interleukin 13, a brain tumorassociated cancer/testis antigen. Molecular Medicine. 2000; 6: 440

10. Debinski W, Gibo DM, Hulet SW, Connor JR, Gillespie GY. Receptor for interleukin 13 is a marker and therapeutic target for human high-grade gliomas. Clinical Cancer Research. 1999; 5: 985-90.

11. Debinski W, Gibo DM, Obiri NI, Kealiher A, Puri RK. Novel anti-brain tumor cytotoxins specific for cancer cells. Nature biotechnology. 1998; 16: 449-53.

12. Debinski W. An immune regulatory cytokine receptor and glioblastoma multiforme: an unexpected link. Critical reviews in oncogenesis. 1998; 9: 255-68.

13. Mintz A, Gibo DM, Slagle-Webb B, Christensent ND, Debinski W. IL-13R $\alpha 2$ is a glioma-restricted receptor for interleukin-13. Neoplasia. 2002; 4: 388-99.

14. Nguyen V, Conyers JM, Zhu D, Gibo DM, Dorsey JF, Debinski W, Mintz A. IL-13Ra2-targeted therapy escapees: biologic and therapeutic implications. Translational oncology. 2011; 4: 390-400.

15. Frosina G. DNA Repair and Resistance of Gliomas to Chemotherapy and Radiotherapy. Molecular Cancer Research. 2009; 7: 989-99. doi: 10.1158/1541-7786. mcr-09-0030.

16. Ramirez Y, Weatherbee J, Wheelhouse R, Ross A. Glioblastoma Multiforme Therapy and Mechanisms of Resistance. Pharmaceuticals. 2013; 6: 1475.

17. Mischel PS, Cloughesy TF. Targeted molecular therapy of GBM. Brain pathology. 2003; 13: 52-61.

18. Lo HW. EGFR-targeted therapy in malignant glioma: novel aspects and mechanisms of drug resistance. Current molecular pharmacology. 2010; 3: 37-52.

19. Nguyen V, Conyers JM, Zhu D, Gibo DM, Hantgan RR, Larson SM, Debinski W, Mintz A. A novel ligand delivery system to non-invasively visualize and therapeutically exploit the IL13R $\alpha 2$ tumor-restricted biomarker. Neurooncology. 2012; 14: 1239-53.

20. Mintz A, Gibo DM, Madhankumar A, Cladel NM, Christensen ND, Debinski W. Protein-and DNA-based active immunotherapy targeting interleukin-13 receptor alpha2. Cancer biotherapy \& radiopharmaceuticals. 2008; 23: 581-9.

21. Nguyen V, Hollingsworth C, Debinski W, Mintz A. A novel ligand delivery system that targets the IL13R $\alpha 2$ tumorrestricted biomarker. Journal of Nuclear Medicine. 2010; 51: 58-58.

22. Beard RE, Abate-Daga D, Rosati SF, Zheng Z, Wunderlich JR, Rosenberg SA, Morgan RA. Gene Expression Profiling using Nanostring Digital RNA Counting to Identify Potential Target Antigens for Melanoma Immunotherapy. Clinical Cancer Research. 2013; 19: 4941-50. doi: 10.1158/1078-0432.ccr-13-1253.

23. Thaci B, Brown CE, Binello E, Werbaneth K, Sampath P, Sengupta S. Significance of interleukin-13 receptor alpha 2targeted glioblastoma therapy. Neuro-Oncology. 2014; 16: 1304-12. doi: 10.1093/neuonc/nou045.

24. Minn AJ, Gupta GP, Siegel PM, Bos PD, Shu W, Giri DD, Viale A, Olshen AB, Gerald WL, Massagué J. Genes that mediate breast cancer metastasis to lung. Nature. 2005; 436: 518-24.

25. Madhankumar A, Mintz A, Debinski W. Alanine-scanning mutagenesis of $\alpha$-helix $D$ segment of interleukin-13 reveals new functionally important residues of the cytokine. Journal of Biological Chemistry. 2002; 277: 43194-205.

26. Mintz A, Gibo DM, Madhankumar A, Debinski W. Molecular Targeting with Recombinant Cytotoxins of Interleukin-13 Receptor $\alpha$ 2-expressing Glioma. Journal of neuro-oncology. 2003; 64: 117-23.

27. Nguyen V, Conyers JM, Zhu D, Gibo DM, Dorsey JF, Debinski W, Mintz A. IL-13R $\alpha 2$-targeted therapy escapees: biologic and therapeutic implications. Translational oncology. 2011; 4: 390-400.

28. Madhankumar A, Slagle-Webb B, Mintz A, Sheehan JM, Connor JR. Interleukin-13 receptor-targeted nanovesicles are a potential therapy for glioblastoma multiforme. Molecular cancer therapeutics. 2006; 5: 3162-9.

29. Debinski W, Thompson JP. Retargeting interleukin 13 for radioimmunodetection and radioimmunotherapy of human high-grade gliomas. Clinical cancer research. 1999; 5: $3143 \mathrm{~s}-7 \mathrm{~s}$.

30. Brown CE, Alizadeh D, Starr R, Weng L, Wagner JR, Naranjo A, Ostberg JR, Blanchard MS, Kilpatrick J, Simpson J, Kurien A, Priceman SJ, Wang X, et al. Regression of Glioblastoma after Chimeric Antigen Receptor T-Cell Therapy. New England Journal of Medicine. 2016; 375: 2561-9. doi:10.1056/NEJMoa1610497.

31. Nguyen V, Mintz A. New frontiers in biomarker-targeted molecular imaging. Cancer Biology \& Therapy. 2009; 8: 2246-9. doi: 10.4161/cbt.8.23.10231.

32. Pandya H, Gibo DM, Debinski W. Molecular Targeting of Intracellular Compartments Specifically in Cancer Cells. Genes Cancer. 2010; 1: 421-33. doi: 10.1177/1947601910375274. 
33. Pandya H, Gibo DM, Garg S, Kridel S, Debinski W. An interleukin 13 receptor $\alpha 2$-specific peptide omes to human Glioblastoma multiforme xenografts. Neuro-Oncology. 2012; 14: 6-18. doi: 10.1093/neuonc/nor141.

34. Solingapuram Sai KK, Almaguel F, Sattiraju A, Herpai D, Debinski W, Mintz A. Radiolabeling and initial biological evaluations of [64Cu]NOTA-Pep-1L for imaging Glioblastoma (GBM). Journal of Nuclear Medicine. 2016; 57: 1100 .

35. Wadas TJ, Anderson CJ. Radiolabeling of TETA- and CB-TE2A-conjugated peptides with copper-64. Nat Protocols. 2007; 1: 3062-8.

36. Anderson CJ, Ferdani R. Copper-64 Radiopharmaceuticals for PET Imaging of Cancer: Advances in Preclinical and Clinical Research. Cancer Biotherapy and Radiopharmaceuticals. 2009; 24: 379-93. doi: 10.1089/ cbr.2009.0674.

37. Guérin B, Ait-Mohand S, Tremblay MC, Dumulon-Perreault V, Fournier P, Bénard F. Total Solid-Phase Synthesis of NOTA-Functionalized Peptides for PET Imaging. Organic Letters. 2010; 12: 280-3. doi: 10.1021/o1902601x.

38. De Silva RA, Jain S, Lears KA, Chong HS, Kang CS, Sun $\mathrm{X}$, Rogers BE. Copper-64 radiolabeling and biological evaluation of bifunctional chelators for radiopharmaceutical development. Nuclear Medicine and Biology. 2012; 39: 1099-104. doi: 10.1016/j.nucmedbio.2012.05.009.

39. VanderVeen N, Paran C, Krasinkiewicz J, Zhao L, Palmer D, Hervey-Jumper S, Ng P, Lowenstein PR, Castro MG. Effectiveness and Preclinical Safety Profile of Doxycycline to Be Used "Off-Label" to Induce Therapeutic Transgene Expression in a Phase I Clinical Trial for Glioma. Human Gene Therapy Clinical Development. 2013; 24: 116-26. doi: 10.1089/humc.2013.139.

40. Li HF, Kim JS, Waldman T. Radiation-induced Akt activation modulates radioresistance in human glioblastoma cells. Radiation Oncology (London, England). 2009; 4: 43-. doi: 10.1186/1748-717X-4-43.

41. Debinski W, Miner R, Leland P, Obiri NI, Puri RK. Receptor for interleukin (IL) 13 does not interact with IL4 but receptor for IL4 interacts with IL13 on human glioma cells. Journal of Biological Chemistry. 1996; 271: 22428-33.

42. Debinski W, Obiri NI, Powers SK, Pastan I, Puri RK. Human glioma cells overexpress receptors for interleukin
13 and are extremely sensitive to a novel chimeric protein composed of interleukin 13 and pseudomonas exotoxin. Clinical Cancer Research. 1995; 1: 1253-8.

43. Craft JM, De Silva RA, Lears KA, Andrews R, Liang K, Achilefu S, Rogers BE. In Vitro and In Vivo Evaluation of a (64)Cu-Labeled NOTA-Bn-SCN-Aoc-Bombesin Analogue in Gastrin-Releasing Peptide Receptor Expressing Prostate Cancer: (64)Cu- NOTA-Bn-SCN-Aoc-Bombesin in Prostate Cancer. Nuclear Medicine and Biology. 2012; 39: 609-16. doi: 10.1016/j.nucmedbio.2011.12.004.

44. Okarvi S. Peptide-based radiopharmaceuticals and cytotoxic conjugates: potential tools against cancer. Cancer treatment reviews. 2008; 34: 13-26.

45. Garanger E, Boturyn D, Dumy P. Tumor targeting with RGD peptide ligands-design of new molecular conjugates for imaging and therapy of cancers. Anti-Cancer Agents in Medicinal Chemistry (Formerly Current Medicinal Chemistry-Anti-Cancer Agents). 2007; 7: 552-8.

46. Debinski W, Gibo DM, Obiri NI, Kealiher A, Puri RK. Novel anti-brain tumor cytotoxins specific for cancer cells. Nature biotechnology. 1998; 16: 449-53.

47. Ferreira CL, Yapp DT, Lamsa E, Gleave M, Bensimon C, Jurek P, Kiefer GE. Evaluation of novel bifunctional chelates for the development of $\mathrm{Cu}$-64-based radiopharmaceuticals. Nuclear Medicine and Biology. 2008; 35: 875-82. doi: 10.1016/j.nucmedbio.2008.09.001.

48. Cutler CS, Wuest M, Anderson CJ, Reichert DE, Sun Y, Martell AE, Welch MJ. Labeling and in vivo evaluation of novel copper(II) dioxotetraazamacrocyclic complexes. Nuclear Medicine and Biology. 2000; 27: 375-80. doi: 10.1016/S0969-8051(00)00101-3.

49. Sai KK, Huang C, Yuan L, Zhou D, Piwnica-Worms D, Garbow JR, Engelbach JA, Mach RH, Rich KM, McConathy J. (18)F-AFETP, (18)F-FET, and (18) F-FDG Imaging of Mouse DBT Gliomas. Journal of nuclear medicine : 2013; 54: 1120-6. doi: 10.2967/ jnumed.112.113217.

50. Mintz A, Gibo DM, Slagle-Webb B, Christensen ND, Debinski W. IL-13Ralpha2 is a glioma-restricted receptor for interleukin-13. Neoplasia. 2002; 4: 388-99. doi: 10.1038/sj.neo.7900234. 